\title{
Subcategory of Evolution within Deviation Category in the English Language
}

\section{Alexander Ptashkin}

Tomsk Polytechnic University

Email: pt.alexandr@gmail.com

\section{Doi:10.5901/mjss.2014.v5n20p2327}

\section{Abstract}

The author describes the language means of expressing the subcategory "Evolution" as the element of the biological component of the deviation category in the English language. The subcategory "Evolution" is considered as the basic element in forming the biological component of deviation category, but the author distinguishes other mental units that are interconnected with the primary category. "Evolution" is mentioned as the subcategory, further analysis gives chance to see the concepts "Mutation" and its components "Beneficial Mutation", "Degenerative Mutation", and "Migration", "Genetic Drift", "Natural Selection" within this subcategory. The author considers the category of deviation, expressed by the words of general semantics with root devia-, and concludes that the concretization of the meanings of mentioned above words occurs by means of the analysis of their contextual correlations with language units, representing the subcategory "Evolution", included in the sphere of deviation. This subcategory is the part within the hierarchical structure of deviation category, the peculiar feature of this structure is the presence of hyper-hyponym relations in it.

Keywords: category, deviation; evolution; lexeme; set phrase; subcategory;

\section{Introduction}

"The cognitive process by means of which linguistic categories are established is known as categorization. Categories have members. <...> Categories are also part of conceptual groupings: they form parts of taxomomies, partonomies, frames and domains" (Radden, 2009). "...categorization is fundamental human ability, but there is not general agreement about the nature of that categorization ability. The classic view of categories is that they have necessary and sufficient conditions for membership. That is, a category is defined by the set of necessary and sufficient features shared by all members" (Corrigan, 1989). "The importance of categorization and concept formation to cognitive development, and to cognition in adults, should not be underestimated. Forming categories reduces demands on our inherently limited memory storage and perceptual process, and without it we would have to remember independently the same or similar information about each individual member of a category" (Rakinson, 2003). "Perceptual categories compute object groups based on their appearance; conceptual categories compute class membership based on an object's role or function in events. Perceptual categories contain detailed information, whereas concepts are relatively crude, abstract, and devoid of specific content" (Damon, 2006). Categories occur at different levels of inclusiveness, with more specific ones nested within more inclusive ones: deviation - evolution - biological evolution - mutation - beneficial mutation lactose tolerance. Normally, one level of specificity in each set, called the basic or generic level of specificity, has a special status, and importance. Apart from the basic level, two further levels of specificity with different characteristics are usually identified: superordinate level and subordinate level. These are not defined simply by their position in the chain there are substantive characteristics that distinguish one level from another (Croft, 2004). "We 'automatically' classify things around us as 'books', 'pencils', 'trees', 'coffee-cup', and so on. And having classified something as a 'book', 'coffee-cup', or whatever, we have access to further knowledge about the object we know how to handle it, what we are supposed to do with it, and so on. In this way, categorization serves to reduce the complexity of the environment. For the most part, categorization seems part and parcel of perception" (Taylor, 2003).

The categorization is the neuroprocess of using steretypical concepts in ordinary or extraordinary mental activity of a human. It will be rough to point out the levels within the categories. The author considers the elements that are distinguished within this category as equal because these mental units can be met in the boundaries of other categories. It does not mean that the classical theory of categories is rejected in this work, but it needs inriching the data because categories are different in its functioning and are reflected in languages in specific way. Neverless, the term subcategory is used in this paper to underline the hierachy of the mental unit. It is necessary to point out that the subcategory is a specification of Deviations, further detalization leads to concepts which are considered as the elements of subcategories. 
The view of the author on the topic of Deviation category and its representatives are shown in the Table 1 and Table 2. This structure is debatable because it reflects the development of language which is the representation of the culture.

This work follows the view that there is no differentiaton between types of linguistic, cultural, psychological, and other categories. In the question of categories (and some other questions) linguistics, culture, psychology, sociology and other sciences that are closely connected with categorization can not be considered separately.

\section{Research Methodology}

For example, the mental unit Evolution is the subcategory in the boundaries of the category of Deviation and it forms basic level. The author follows the classical view and presents the category of Deviation as the system with three main levels: superordinate, basic and subordinate ones. But alternative structure can be used for more true to life usage of the semantic category of Deviation.The semantic analysis of the vocabulary associated with the superordinate level of Deviation Category let us define the number of lexemes which present this mental unit in its broad meanings. In English language these are the lexemes and phrases with the root devia- from deviate - "turn aside. XVII. f. pp. stem of late L. dēviāre, f. dē DE- 2 + via way. So devia·TION. XVII; - F. - medL" (Skeat, 1980): deviance, deviancy, deviant, deviation, deviator, deviatory, etc. (Fulcher, 2011). In this category the middle level of biological component of Deviation is formed by means of the subcategory Evolution: deviation - evolution - mutation - degenerative mutation. The author considers it necessary to mention further elements in the hierachy of Deviation category being the concepts: deviation (highest level category) - evolution (basic level - subcategory) - mutation: beneficial mutation (third level - concept). The term concept can be detalized: megaconcept, concept. The position of this or that element in the category depends on the degree of their abstraction.

The classical scheme does not reflect the development of the mental units: sometimes, the concepts can "die" within the boundaries of a certain subcategory and category. This is minor remark, and it does not happen constantly.

It is advisable to form the hierachy of "the category with independent elements" where subcategories can be taken and used within other categories. For example, the concept Mutation can be met as the element of the subcategories Evolution and Inferiority. This structure is debatable and needs further correction analyzing elements of semantic field of Deviation category in the frame of biological component. See Table 1.

The linguistic structuring of biological component of Deviation category, and distinguishing the subcategories Evolution and Inferiority is the result of existance of language and other sciences' views: sociology, cultural studies, etc. The peculiarity of the subcategories Evolution and Inferiority is that the last one means the change of one person, not population whereas the subcategory Evolution involves the sense: deviation (positive or negative) of a certain group.

The distinctive peculiarity of Deviation is its survival in many spheres of human activity. The problem about the components of Deviation is debatable. The analysis of special literature enabled to define basic elements of structure in Deviation Category.

Table 1. The hierachy of the type "category - subcategory - concept" in biological component of Deviation category in the English category.

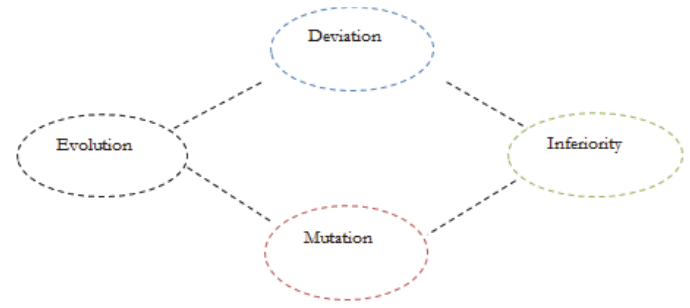

The common elements of Deviation present the phenomenon under study as the combination of three main components: 1) techno-biological, 2) legal-regulatory, 3) moral-ethic. The focus of this paper is Evolution as a part of biological element within Deviation Category. The technical point of Deviation category is omitted here. The subcategory Inferiority is taken as the additional element to show the complex character of Deviation category and functioning of the concept Mutation.

The biological element of Deviation Category defines "evolution as any change in allele (or gene) frequence in a population over time following the origin of life" (Jappah, 2003). "Evolution consists of changes in the heritable traits of a population of organisms as successive generations replace one another. It is populations of organisms that evolve, not 
individual organisms" (Evolution Resources, 2014). "The population is the so-called unit of evolution. Genes, individuals, and species also play a role, but it is the change in populations that characterizes organic evolution" (Mayr, 2014). "Evolution is the process by which modern organisms have descended from ancient ancestors. Evolution is responsible for both the remarkable similarities we see across all life and the amazing diversity of that life. $<\ldots>$ Fundamental to the process is genetic variation upon which selective forces can act in order for evolution to occur" (Understanding Evolution, 2014).

The above-mentioned meanings of the term Evolution give the opportunity to see the mechanisms of structuring the data about this phenomenon.

\section{Findings and Discussion}

The structure in Table 2 reflects only the knowledge about biological aspect, it does not include the cultural, social data. Within the biological component the concept Mutation is functioning in two main streams: Beneficial Mutation and Degenerative Mutation. The basis for pointing out the elements of the biological component of Deviation Category was special literature, dictionaries (Bowler, 2003; Ruse, 2009; Larson, 2006; Fleisher, 2006; Barrows, 2011; Narang, 1995).

Table 2. The subcategory Evolution as a part of the category of Deviation within biological component.

\begin{tabular}{|c|}
\hline Deviation \\
\hline I \\
\hline Evolution \\
\hline I \\
\hline$\frac{\text { Mutation }}{\text { Migration }}$ \\
Satural Selection \\
\hline
\end{tabular}

Evolution is widely spread in special and imaginative literature and journalistic lexis. In the basic level this subcategory is presented by the following lexemes: "rise, development, adaptation, natural selection, Darwinism, survival of the fittest, evolvement, etc." (Collins Dictionary, 2014); "organic evolution, phylogenesis, phylogeny" (WordNet 3.1, 2014); "biological science, biology, anamorphism, anamorphosis, anthropogenesis, anthropogeny, emergent evolution, macroevolution, microevolution, biological process, organic process, speciation" (Free Dictionary, 2014; Thesaurus, 2014). They form the central part of the semantic field of the subcategory Evolution in the sense of biology. Other lexical units are omitted.

The concept Mutation in the boundaries of the subcategory Evolution is presented with the primary elements: carrier, carry, chromosome, clone, cloning, cross, cross-fertilise, cross-fertilization, deoxyribonucleic acid, DNA, DNA fingerprinting, dominant, double helix, gene, gene pool, gene therapy, genetic, genetically modified, genetic code, genetic engineering, genetic fingerprinting geneticist, genetic modification, genetic profiling, genetics, genetic screening, genome, genotype, GM, GMO (genetically modified organism), hard-wired, hereditary, heredity, heterozygous, homozygous, inherit, inheritance, inherited, locus, mutagen, mutant, mutate, mutation, pass on, recessive, reproductive cloning, sequence, sex chromosome, therapeutic cloning, transgenic, vector, X-chromosome, Y-chromosome, etc (McMillan Dictionary, 2014).

The concept Mutation has further detalization: Beneficial Mutation and Degenerative Mutation. For example, the lactose tolerance is a Beneficial Mutation whereas hypertrichosis is a Degenerative Mutation. In any case any mutation is marked negatively. The final level of Deviation category within biological component is presented by concrete members. This level is expressed by the lexemes and set phrases: Uner Tan syndrome, Hutchinson-Gilford Progeria, Hypertrichosis, Epidermodysplasia Verruciformis, Severe Combined Immunodeficiency Disorder, Lesch-Nyhan Syndrome, Ectrodactyly, Proteus Syndrome, Trimethylaminuria, Marfan Sydrome, sickle-cell anemia, lactose tolerance, ccr5-32 mutation, etc. This list is presented by positive and negative mutations. These are only examples, the full list of components will be formed as a result of contextual analysis. Here terms of biological character are considered.

Some concrete kinds of meanings of lexemes, phrases that characterize biological component of deviation category can be traced in the following contexts:

Natural selection (the adaptive component of evolution) is thought to work like a tinkerer, and a tinkerer usually 
does not rebuild the house (Koonin, 2011).

Within this context the lexeme evolution is presented with the direct meaning: any change in a population, and it defines the basic level of deviation category. The set phrase natural selection denotes the third level of conceptualization.

Most people of northern European ancestry, however, are lactose tolerant and can drink milk throughout their lives. We now know that, about 10,000 years ago when Europeans began to domesticate cows, a change (mutation) occurred in a few individuals that weakened the lactose "control gene" and allowed people to continue to consume milk after infancy. Over time, this beneficial mutation allowing people to continue drinking milk spread throughout Europe and eventually overseas as people migrated (Golanty, 2011).

In this context, the lactose tolerance is concerned here. The lexemes change and mutation refer to the third level of categorization, whereas the set phrase lactose tolerant is the representative of the lower level of deviation category.

As a result of mutations, races developed identifying physical characteristics. Skin colors, physical features and even body types among races may well be due to the fact that they served some useful purpose in their original environments. <...> Many diseases and genetic abnormalities are the result of mutations, which was a deviation from the original genetic structure of Adam and Eve (not sin) (Hall, 2006).

The author of this example considers race mutations. The semantics of lexeme deviation specifies the highest level of deviation category. The lexeme mutation and set phrase genetic abnormality indicate the third level of categorization.

Those with sickle-cell anemia in the same area are quite resistant to a deadly strain of malaria because their atypical blood cells collapse or "sickle," destroying the developing parasite. Evolutionists maintain this is a "beneficial mutation" or overdominance. But is it? Put another way, is sickle-cell anemia a fitting example of the continuous genetic expansion required by evolution (Sherwin, 2005).

In this example the disease called sickle-cell anemia is mentioned. The name of this disease, sickle-cell anemia, represents the lowest level of Deviation category. The lexemes evolution and evolutionist indicate the basic level of categorization. The set phrase beneficial mutation define the third level of Deviation category.

The purpose of this research is to determine when in the process of human evolution nasal septal deviation first occurred. There is a higher incidence of nasal septal deviations in man, while the septum of anthropoid ape is vertical and has not been found to have nasal septal deviations (Takahashi, 1997).

In the light of this article, nasal septal deviation is observed. The above-mentioned set phrase defines the biological divergence and refers to the highest level of conceptualization. The lexeme evolution is the primary word for the subcategory of Evolution.

\section{Concluding Remarks}

Thus, the whole structure of the subcateogry Evolution can be formed in the following way: deviation - evolution mutation / migration / genetic drift / natural selection - beneficial mutation / degenerative mutation, etc. - lactose tolerance, etc. The subcategory Evolution represents the basic level of biological component of Deviation category. "The contextual semantics of the key lexemes with the root devia- expresses the content of the highest level of biological component of Deviation category". The concept Mutation is the representative of the third level of categorization. The paper proves the fact that the highest level of mental unit is the category, subcategory is formed in the middle of such hierachy, the third and other levels are small components, concepts.

The means of biological component of Deviation category are the corresponding lexemes and set phrases: deviation, evolution, mutation, beneficial mutation, degenerative mutation, etc.

The characteristics of deviation of biological type have the negative evaluation (Ptashkin 2013a; 2013b; 2014).

The peculiarities of the structure can be traced analyzing the variants of meanings of the lexemes, phrases representing the concrete levels of the category. These meanings enable to specify the semantics of language units that are under analysis.

Deviation category and subcategory Evolution are marked cognitively and culturally: the specification of the concepts Mutation, Beneficial Mutation, Degenerative Mutation can be carried out by means of contexual analysis of lexemes and set phrases.

\section{References}

Barrows, E. M. (2011). Animal Behaviour Desk Reference: A Dictionary of Animal Behaviour, Ecology, and Evolution. Boca Raton: CRC Press.

Bowler, P. J. (2003). Evolution: The History of an Idea. Oakland: University of California Press. 
Collins Dictionary (2014). Evolution. Retrieved May 5, 2014, from http://www.collinsdictionary.com.

Corrigan, R. (1989). Linguistic Categorization. Amsterdam: John Benjamins Publishing.

Croft, W. (2004). Cognitive Linguistics. New York: Cambridge University Press.

Damon, W. (2006). Handbook of Child Psychology: Cognition, Perception, and Language. Hoboken: John Wiley \& Sons.

Evolution Resources (2014). Evolution. Retrieved April 13, 2014, from http://www.nas.edu/evolution/Definitions.html.

Fleisher, P. (2006). Evolution. Minneapolis: Twenty-First Century Books.

Free Dictionary (2014). Evolution. Retrieved June 15, 2014, from http://www.thefreedictionary.com/evolution.

Fulcher, J. (2011). Sociology. New York: Oxford University Press.

Golanty, E. (2011). Human Sexuality: The Basics. Sudbury: Jones \& Barlett Learning.

Hall, L. (2006). Timely Reflections: A Venture in Philosophical Investigation. Bloomington: AuthorHouse.

Jappah, D. (2007). Evolution: A Grand Monument to Human Stupidity. Raleigh: Lulu.com.

Koonin, E. V. (2011). The Logic of Chance: The Nature and Origin of Biological Evolution. New Jersey: FT Press, New Jersey.

Larson, E. J. (2006). Evolution: The Remarkable History of a Scientific Theory. New York: Random House LLC.

Mayr, E. (2014). What Evolution is: From Theory to Fact. Paris: Hachette UK.

McMillan Dictionary (2014). Mutation. Retrieved April 2, 2014, from www.macmillandictionary.com/thesaurus-category/british/Genesand-genetics.

Narang, K. (1995). Encyclopaedic Dictionary of Genetics and Organic Evolution. New Delhi: Anmol Publications Pvt. Limited.

Ptashkin, A. S. (2013a). Concept "Genocide" as the Form of the Legal-Regulatory Component in the Deviation Category in the English Language. World Applied Sciences Journal, No. 23(5), pp. 621-627.

Ptashkin, A. S. (2013b). The Concept "Ethnocide" Within the Category of Deviation in the English Language. World Applied Sciences Journal, No. 28(6), pp. 826-828.

Ptashkin, A. S. (2014). The Concepts of "Beauty" and "Pathology" within the Biological Component of Deviation Category (in the English Language). Xlinguae: European Scientific Language Journal, No. 7 (1), pp. 21-28.

Radden, G. (2009). Cognitive English Grammar. Amsterdam: John Benjamins Publishing Company.

Rakinson, D. H. (2003). Early Category and Concept Development: Making Sense of the Blooming, Buzzing Confusion. New York: Oxford University Press.

Ruse, M. (2009). Evolution: The First Four Billion Years. Cambridge: Harvard University Press.

Sherwin, F. (2005). Evolution and Malaria. Acts \& Facts, 34 (4). Retrieved March 20, 2005, from http://www.icr.org/article/evolutionmalaria.

Skeat, W. W. (1980). A Concise Etymological Dictionary of the English Language. New York: The Putnam Publishing Group.

Takahashi, R. (1997). The Formation of Nasal Septum Deviation in Human Evolution. Rhinology, 15 (4), pp.159-165.

Taylor, J. R. (2003). Linguistic Categorization. New York: Oxford University Press.

Thesaurus (2014). Evolution. Retrieved April 7, 2014, from http://thesaurus.com/evolution.

Understanding Evolution (2014). Mechanisms: the Processes of Evolution. Retrieved March 14, 2014, from http://evolution.berkeley.edu levolibrary/article/0_0_0/evo_14.

WordNet 3.1 (2014). Evolution. Retrieved May 9, 2014, from http://wordnetweb.princeton.edu/perl/webwn?s=evolution. 